\title{
ANALISIS PERILAKU MASYARAKAT DALAM MEMILIH MEREK HANDPHONE DENGAN MENGGUNAKAN ANALISIS FAKTOR (Studi Kasus Mahasiswa Universitas Udayana)
}

\author{
Sang Ayu Putri Indria Rantasari ${ }^{\S 1}$, Ni Luh Putu Suciptawati ${ }^{2}$, \\ Ni Ketut Tari Tastrawati ${ }^{3}$ \\ ${ }^{1}$ Jurusan Matematika Fakultas MIPA - Universitas Udayana [Email: sangayuindria@yahoo.co.id] \\ ${ }^{2}$ Jurusan Matematika Fakultas MIPA - Universitas Udayana [Email: putusuciptawati@yahoo.co.id] \\ ${ }^{3}$ Jurusan Matematika Fakultas MIPA - Universitas Udayana [Email: taritastrawati@ yahoo.com] \\ ${ }^{\S}$ Corresponding Author
}

\begin{abstract}
The purpose of this study is to determine factors that influence consumer's decisions to choose a brand of mobile phone and to determine the dominant factor influencing consumer's decision in choosing brand of mobile phone. The method used is factor analysis. Factor analysis is one part of the analysis of several variables that are used to reduce the data, which is a process to summarize a number of independent variables associated with the factors named mapped or grouped into a new variable. The results showed that there are seven factors that influence consumers to choose the brand of mobile phone: the quality factor, brand, features, product durability, shape or model, price, and warranty. While among the seven factors, the quality factor is a dominant factors that affect consumers to choose brand of mobile phone.
\end{abstract}

Keywords: Brand of Mobile Phone, Udayana University Student, Factor Analysis

\section{PENDAHULUAN}

Kemajuan teknologi yang sedemikian cepat membawa pengaruh pada setiap aspek kehidupan masyarakat, salah satunya adalah semakin meningkatnya kebutuhan masyarakat terhadap komunikasi. Dengan demikian dibutuhkan suatu produk yang dapat membantu masyarakat melakukan komunikasi dengan mudah yaitu handphone. Hal tersebut menyebabkan beredarnya berbagai macam merek handphone di pasaran. Agar dapat bersaing antarmerek handphone maka dibutuhkan strategi yang tepat untuk menarik minat konsumen dalam memilih merek handphone tersebut. Dalam membentuk strategi yang tepat maka setidaknya setiap produsen handphone harus mengetahui faktor-faktor yang menyebabkan konsumen lebih memilih merek handphone tersebut dibandingkan merek handphone lainnya. Dengan memanfaatkan informasi terkait faktor-faktor yang memengaruhi setiap konsumen dalam memilih merek handphone maka produsen handphone dapat menciptakan handphone yang sesuai dengan keinginan konsumen dan banyak diminati oleh masyarakat yang menyebabkan tingkat penjualan produk akan menjadi semakin meningkat.

Hal ini juga didukung oleh beberapa teori. Menurut Kotler dan Amstrong [1] ada beberapa hal yang dijadikan dasar oleh konsumen dalam pengambilan keputusan pembelian yaitu atribut yang menyertai atau melengkapi produk seperti harga, merek, kualitas, dan kemasan produk. Dalam menilai sebuah kualitas ada beberapa hal yang diperhatikan oleh konsumen yaitu kinerja, tampilan, kehandalan, kesesuaian, daya tahan, kemampuan pelayanan, keindahan model atau bentuk, dan kualitas yang dipersepsikan (Tjiptono [2]). 
Berdasarkan permasalahan tersebut, maka tujuan dalam penelitian adalah untuk mengetahui faktor-faktor yang memengaruhi konsumen dalam memilih merek handphone, dan faktor yang dominan berpengaruh dalam memilih merek handphone. Metode yang digunakan adalah analisis faktor.

Analisis faktor dipilih karena variabelvariabel yang terdapat dalam penelitian ini berskala interval. Selain itu analisis faktor merupakan metode yang dapat digunakan untuk mereduksi data yaitu suatu proses untuk meringkas sejumlah variabel independen yang saling berkorelasi untuk dikelompokan menjadi sebuah variabel baru yang diberi nama faktor. Prinsip dasar analisis faktor adalah mengekstrasi sejumlah faktor (common factor) dari gugusan variabel asal $X_{1}, X_{2}, X_{3}, \ldots, X_{p}$, sehingga banyaknya faktor lebih sedikit dari banyaknya variabel asal $X$ yang tersimpan dalam sejumlah faktor.

Dalam analisis faktor, ada beberapa tahapan yang harus dilakukan, yaitu pengujian matriks korelasi, pencarian faktor, dan rotasi faktor. Pengujian matriks korelasi pada analisis faktor dilakukan dengan tiga macam uji statistika yaitu: tahap pertama adalah dengan melakukan uji Kaiser Meyer Oikin (KMO) bertujuan untuk mengetahui semua data yang terambil telah layak untuk analisis faktor. Dengan kriteria ukuran KMO disarankan paling tidak lebih besar sama dengan 0,80 tetapi apabila nilai KMO lebih besar sama dengan 0,50 masih dapat disimpulkan jumlah data yang digunakan layak untuk analisis faktor (Widarjono [3]).

Tahap kedua adalah dengan melakukan uji Bartlett's Test of Sphericity bertujuan untuk mengetahui hubungan antarvariabel. Jika terdapat hubungan pada setiap variabel maka analisis faktor layak untuk digunakan.

Tahap ketiga adalah dengan melakukan uji Measures of Sampling Adequacy (MSA) bertujuan mengetahui kecukupan data atau sampel. Angka MSA berkisar dari 0 sampai 1 dengan kriteria untuk nilai MSA sama dengan 1, variabel tersebut dapat diprediksi sangat baik dan dapat dianalisis lebih lanjut. Nilai MSA lebih besar sama dengan 0,5; variabel masih bisa diprediksi dan bisa dianalisis lebih lanjut (Hair, et.al. [4]).

Setelah melakukan pengujian matriks korelasi maka tahap selanjutnya yang dapat dilakukan adalah penentuan banyaknya faktor. Keputusan pengambilan jumlah faktor didasarkan pada nilai eigen dari matriks korelasi antarvariabel. Apabila nilai eigen lebih besar dari satu akan dipertahankan dan dapat digunakan sebagai sebuah faktor sedangkan nilai egien lebih kecil dari satu maka tidak dapat digunakan. Kemudian dilanjutkan dengan ekstraksi faktor.

Kemudian dilanjutkan dengan melakukan rotasi faktor. Rotasi faktor dilakukan karena metode ekstraksi faktor belum mampu menghasilkan faktor baru yang lebih mudah untuk diinterpretasikan maka tujuan dari rotasi faktor ini agar dapat memperoleh struktur faktor yang lebih sederhana agar mudah diinterpretasikan. Rotasi faktor dilakukan dengan cara merotasikan loading factor.

Rotasi faktor dapat dibagi menjadi dua macam yaitu: pertama rotasi orthogonal, yang mempertahankan sumbu antarfaktor tetap tegak lurus setelah dirotasi. Dengan melakukan rotasi ini, maka setiap faktor saling bebas terhadap faktor lain karena sumbunya saling tegak lurus. Rotasi orthogonal ada tiga macam yaitu: varimax, quartimax, equamax

Sedangkan rotasi oblique dimana sumbu faktor yang kedudukannya saling membentuk sudut dengan besar sudut tertentu maka korelasi antarfaktor masih diperhitungkan karena sumbu faktor tidak saling tegak lurus dengan sumbu faktor yang lainnya. Rotasi oblique ada empat macam yang populer yaitu: quartimin, biquartimin, covarimin, dan oblimin.

Secara umum model untuk analisis faktor sebagai berikut:

$X_{p}-\mu_{p}=l_{p 1} F_{1}+l_{p 2} F_{2}+l_{p 3} F_{3}+. .+l_{p m} F_{m}+\varepsilon_{p}$ keterangan:

$X_{p} \quad=$ variabel asal

$l_{p m}=$ faktor pembobot (factor loading) dari 


$$
\begin{aligned}
& \text { variabel ke- } p \text { pada faktor ke-m } \\
\mathrm{F}_{\mathrm{m}}= & \text { faktor bersama (common factors) ke- } m \\
\mu_{p}= & \text { rataan ke- } p \\
m \quad= & \text { banyaknya faktor bersama (common } \\
& \text { factors) } \\
\varepsilon_{p} \quad & \text { galat (errors) atau faktor spesifik }
\end{aligned}
$$

Apabila ada sebanyak $p$ variabel asal, model analisis faktor diubah menjadi sebagai berikut:

$X_{1}-\mu_{1}=l_{11} F_{1}+l_{12} F_{2}+l_{13} F_{3}+\cdots .+l_{1 m} F_{m}+\varepsilon_{1}$

$X_{2}-\mu_{2}=l_{21} F_{1}+l_{22} F_{2}+l_{23} F_{3}+\cdots .+l_{2 m} F_{m}+\varepsilon_{2}$

$X_{p}-\mu_{p}=l_{p 1} F_{1}+l_{p 2} F_{2}+l_{p 3} F_{3}+\cdots .+l_{p m} F_{m}+\varepsilon_{p}$

Model analisis faktor dapat juga ditulis dalam bentuk notasi matriks sebagai berikut:

$$
X_{(p \times 1)}-\mu_{(p \times 1)}=L_{(p \times m)} F_{(m \times 1)}+\varepsilon_{(p \times 1)}
$$

Namun asumsi tambahan tentang vektor $F$ dan $\varepsilon$ pada persamaan di atas menunjukkan adanya hubungan peragam sebagai berikut (Chatfield \& Collins [5]):

$$
\begin{aligned}
& \text { 1. } E(F)=0_{(m \times 1)}, \quad \operatorname{Cov}(F)=E\left[F F^{\prime}\right]= \\
& I_{(m \times m)} \\
& \text { 2. } E(\varepsilon)=0_{(p \times 1)}, \\
& \operatorname{Cov}(\varepsilon)=E\left[\varepsilon \varepsilon^{\prime}\right]=\Psi_{(p \times p)}= \\
& {\left[\begin{array}{ccc}
\psi_{1} & \cdots & 0 \\
\vdots & \ddots & \vdots \\
0 & \cdots & \psi_{p}
\end{array}\right]}
\end{aligned}
$$

3. Jika $F$ dan $\varepsilon$ saling bebas, maka

$$
\operatorname{Cov}(\varepsilon, F)=E\left(\varepsilon F^{\prime}\right)=0_{(p \times m)}
$$

Asumsi tersebut dalam hubungannya dengan persamaan pada model analisis faktor dalam bentuk notasi matriks pertama merupakan model faktor orthogonal, dalam notasi matriks ditulis sebagai berikut:

$$
X_{(p \times 1)}=\mu_{(p \times 1)}+L_{(p \times m)} F_{(m \times 1)}+\varepsilon_{(p \times 1)}
$$

\section{METODE PENELITIAN}

Data yang digunakan pada penelitian ini adalah data primer yang diperoleh dari penyebaran kuesioner sebanyak 400 mahasiswa Universitas Udayana pengguna merek handphone Nokia, Samsung, Blackberry, dan produk handphone yang berasal dari Cina.

Teknik pengambilan sampel yang digunakan adalah snowball sampling. Metode penarikan sampel ini dilakukan secara berantai dengan meminta bantuan pada responden yang telah diwawancari atau telah melakukan pengisian kuesioner penelitian untuk menyebarkan kuesioner kepada responden yang lainnya (Purwandari [6]).

Adapun variabel yang digunakan dalam penelitian ini yang dibagi menjadi beberapa indikator sebagai berikut: (1) Harga, (2) Kualitas, (3) Bentuk atau model, (4) Fitur, (5) Garansi, (6) Brand atau merek.

Indikator-indikator yang terdapat pada setiap variabel dalam penelitian ini didasari dari beberapa sumber. Untuk indikator yang terdapat pada variabel harga, bentuk atau model, dan fitur didasari dari penelitian yang dikemukakan oleh Sujana [7]. Sedangkan untuk indikator yang terdapat pada variabel kualitas, garansi, dan merek berdasarkan dari Tjiptono [2] dan juga Kotler \& Amstrong [1].

Langkah-langkah yang dilakukan dalam metode penelitian ini adalah:

1. Membuat kuesioner yang berisi daftar pertanyaan terkait dengan penelitian.

2. Menyebarkan dan menguji validitas dan reliabilitas kuesioner sebanyak 40 kuesioner kepada responden.

3. Menyebarkan kembali kuesioner yang dibuat sebanyak 400 kepada responden.

4. Pengumpulan data dari pengisian kuesioner oleh responden dan menguji kelayakan kuesioner yang telah diisi oleh responden dengan melakukan uji validitas dan reliabilitas.

5. Menganalisis data dengan analisis faktor dengan tahapan-tahapan sebagai berikut:

a. Membentuk matriks korelasi antarvariabel

b. Melakukan pengujian terhadap matriks korelasi antarvariabel dengan tiga uji statistic yaitu Uji Kaiser Meyer Oikin (KMO) bertujuan untuk mengetahui apakah semua data yang telah terambil telah layak untuk analisis faktor, Uji Bartlett bertujuan untuk mengetahui apakah terdapat hubungan antarvariabel, Uji Measures of 
Sampling Adequacy (MSA) bertujuan mengetahui kecukupan data atau sampel.

c. Melakukan ekstraksi faktor yang bertujuan untuk mengetahui jumlah faktor yang terbentuk dari data yang ada. Metode ekstrasi yang digunakan adalah Analisis Komponen Utama (Principal Components Analysis)

d. Melakukan rotasi faktor yang bertujuan agar dapat memperoleh struktur faktor yang lebih sederhana agar mudah diinterpretasikan. Rotasi faktor yang digunakan adalah rotasi Orthogonal dengan metode varimax

e. Menginterpretasikan hasil penelitian.

\section{HASIL DAN PEMBAHASAN}

\section{Uji Validitas dan Reliabilitas Kuesioner}

Uji validitas dan reliabilitas pada data dari hasil penyebaran 400 kuesioner kepada mahasiswa.

Tabel 1.Uji Validitas \& Reliabilitas Kuesioner

\begin{tabular}{|c|c|c|c|}
\hline $\begin{array}{c}\text { Indikator } \\
\text { Variabel }\end{array}$ & $\mathrm{R}$ & $\mathrm{r}$ tabel & Ket \\
\hline $\mathrm{X}_{1}$ & 0,223 & 0,0824 & Valid \\
\hline $\mathrm{X}_{2}$ & 0,306 & 0,0824 & Valid \\
\hline $\mathrm{X}_{3}$ & 0,339 & 0,0824 & Valid \\
\hline $\mathrm{X}_{4}$ & 0,526 & 0,0824 & Valid \\
\hline $\mathrm{X}_{5}$ & 0,448 & 0,0824 & Valid \\
\hline $\mathrm{X}_{6}$ & 0,661 & 0,0824 & Valid \\
\hline $\mathrm{X}_{7}$ & 0,608 & 0,0824 & Valid \\
\hline $\mathrm{X}_{8}$ & 0,423 & 0,0824 & Valid \\
\hline $\mathrm{X}_{9}$ & 0,637 & 0,0824 & Valid \\
\hline $\mathrm{X}_{10}$ & 0,684 & 0,0824 & Valid \\
\hline $\mathrm{X}_{11}$ & 0,685 & 0,0824 & Valid \\
\hline $\mathrm{X}_{12}$ & 0,643 & 0,0824 & Valid \\
\hline $\mathrm{X}_{13}$ & 0,455 & 0,0824 & Valid \\
\hline $\mathrm{X}_{14}$ & 0,567 & 0,0824 & Valid \\
\hline $\mathrm{X}_{15}$ & 0,635 & 0,0824 & Valid \\
\hline $\mathrm{X}_{16}$ & 0,547 & 0,0824 & Valid \\
\hline $\mathrm{X}_{17}$ & 0,528 & 0,0824 & Valid \\
\hline $\mathrm{X}_{18}$ & 0,653 & 0,0824 & Valid \\
\hline $\mathrm{X}_{19}$ & 0,408 & 0,0824 & Valid \\
\hline $\mathrm{X}_{20}$ & 0,549 & 0,0824 & Valid \\
\hline $\mathrm{X}_{21}$ & 0,562 & 0,0824 & Valid \\
\hline $\mathrm{X}_{22}$ & 0,467 & 0,0824 & Valid \\
\hline $\mathrm{X}_{23}$ & 0,551 & 0,0824 & Valid \\
\hline $\mathrm{X}_{24}$ & 0,544 & 0,0824 & Valid \\
\hline Reliabilitas & 0,885 & & Reliabel \\
\hline & \multicolumn{2}{|l}{} \\
\hline
\end{tabular}

Tabel 1 menunjukkan bahwa semua item penyusun variabel penelitian signifikan dan memenuhi syarat validitas. Hal ini dapat dilihat dari nilai koefisien korelasi (R) tiap item yang diperoleh lebih besar dari $\mathrm{r}$ tabel dengan $\mathrm{n}=$ 400 dan derajat bebas $n-2(d b=398)$ dengan $\alpha$ adalah 0,05 .

Uji reliabilitas pada Tabel 1 menunjukkan bahwa kuesioner yang digunakan dalam penelitian bersifat reliabel. Hal ini dapat dilihat dari nilai $\mathrm{R}$ Alpha Cronbach's sebesar 0,885 lebih besar dari 0,5 .

\section{Analisis Faktor}

\section{Uji Kelayakan Data}

Langkah pertama yang dilakukan sebelum melakukan analisis faktor adalah menguji kelayakan data. Uji kelayakan dilakukan melalui tiga tahapan.

Tahap pertama adalah uji KMO yang menghasilkan nilai KMO yang cukup tinggi lebih besar dari 0,5 yaitu sebesar 0,851 ini berarti semua data yang terambil telah layak untuk analisis faktor, dan untuk tahap kedua uji Bartlett's Test of Sphericity juga sudah signifikan karena nilainya 0,000 kurang dari taraf nyata $(\alpha) 0,05$ ini berarti terdapat korelasi pada setiap variabel. Sedangkan untuk uji MSA, semua variabel memiliki nilai MSA lebih besar dari 0,5 ini berarti data atau sampel sudah cukup dan dapat dianalisis lebih lanjut.

\section{Penentuan Banyaknya Faktor}

Penentuan banyaknya faktor dilakukan dengan cara ekstraksi faktor. Metode ekstraksi yang digunakan dalam penelitian ini adalah Analisis Komponen Utama. Dengan kriteria penentuan faktor yang memiliki nilai eigen lebih besar dari satu akan dipertahankan dan dapat dijadikan sebuah faktor. Faktor yang terekstrak berjumlah 7 faktor dengan tingkat kemampuaan untuk menjelaskan secara bersama-sama variabilitas total dari indikator yang ada sebesar 64,939\% dengan rincian sebagai berikut: faktor pertama sebesar $29,823 \%$ dengan nilai eigen 7,157 ; kedua sebesar $9,028 \%$ dengan nilai eigen 2,167; 
ketiga sebesar $6,459 \%$ dengan nilai eigen 1,550 ; keempat $5,498 \%$ dengan nilai eigen 1,319; kelima 5,263\% dengan nilai eigen 1,263; keenam 4,543\% dengan nilai eigen 1,090; dan ketujuh 4,325\% dengan nilai eigen 1,038 .

\section{Rotasi Faktor}

Rotasi faktor dilakukan untuk mendapatkan struktur faktor yang lebih sederhana. Dengan ketentuan nilai faktor pembobot harus lebih besar dari 0,5. Maka dengan mudah mengetahui indikator-indikator variabel yang masuk ke dalam satu faktor. Dalam penelitian ini metode rotasi faktor yang digunakan adalah metode Varimax

Faktor pertama dinamakan faktor kualitas yang terdiri dari kualitas gambar yang diambil $\left(\mathrm{X}_{10}\right)$, resolusi kamera $\left(\mathrm{X}_{9}\right)$, fitur-fitur canggih $\left(\mathrm{X}_{18}\right)$, kelengkapan fitur $\left(\mathrm{X}_{15}\right)$, model yang tidak ketinggalan zaman $\left(\mathrm{X}_{12}\right)$, desain yang menarik $\left(\mathrm{X}_{11}\right)$, kapasitas memori $\left(\mathrm{X}_{6}\right)$, ketajaman layar $\left(\mathrm{X}_{7}\right)$. Pada faktor pertama mampu menjelaskan varians sebesar 29,823\% sekaligus menjadi faktor yang dominan memengaruhi konsumen dalam memilih merek handphone. Dengan indikator yang paling dominan adalah kualitas gambar atau foto yang diambil yang menjadi pertimbangan konsumen memilih merek handphone tersebut.

Faktor kedua dinamakan faktor merek yang terdiri dari kepercayaan terhadap merek $\left(\mathrm{X}_{21}\right)$, pelayanan yang baik untuk pengguna garansi $\left(\mathrm{X}_{20}\right)$, kesetian terhadap merek $\left(\mathrm{X}_{22}\right)$, dan kenyamanan dalam menggunakan merek $\left(\mathrm{X}_{23}\right)$. Pada faktor kedua mampu menjelaskan varians sebesar 9,028\%. Pada faktor kedua ini kepercayaan terhadap merek handphone tersebut yang menjadi pertimbangan konsumen memilih merek handphone tersebut.

Faktor ketiga dinamakan faktor fitur yang terdiri dari fitur yang sudah sesuai dengan kebutuhan pengguna $\left(\mathrm{X}_{17}\right)$, ukuran handphone $\left(\mathrm{X}_{14}\right)$, kemudahan dalam menggunakan menu fitur handphone $\left(\mathrm{X}_{16}\right)$. Pada faktor ketiga mampu menjelaskan varians sebesar $6,459 \%$. Pada faktor ketiga ini fitur-fitur yang sudah sesuai dengan kebutuhan konsumen yang menjadi pertimbangan konsumen memilih merek handphone tersebut.

Faktor keempat dinamakan faktor daya tahan produk yang terdiri dari daya tahan baterai $\left(\mathrm{X}_{5}\right)$, daya tahan produk seperti tahan terhadap air, benturan, dan lain-lain $\left(\mathrm{X}_{8}\right)$, kejernihan suara $\left(\mathrm{X}_{4}\right)$. Pada faktor keempat mampu menjelaskan varians sebesar 5,498\%. Pada faktor keempat ini daya tahan baterai dari handphone tersebut yang menjadi pertimbangan konsumen memilih merek handphone tersebut.

Faktor kelima dinamakan faktor bentuk atau model yang terdiri dari warna handphone $\left(\mathrm{X}_{13}\right)$, dan merek terkenal $\left(\mathrm{X}_{24}\right)$. Faktor kelima mampu menjelaskan varians sebesar 5,263\%. Pada faktor kelima ini warna handphone menjadi pertimbangan konsumen dalam memilih merek handphone tersebut.

Faktor keenam dinamakan faktor harga yang terdiri dari harga jual kembali $\left(\mathrm{X}_{3}\right)$, dan harga terjangkau $\left(\mathrm{X}_{1}\right)$. Faktor keenam mampu menjelaskan varians sebesar 4,543\%. Pada faktor keenam ini harga jual kembali merek handphone tersebut menjadi pertimbangan konsumen dalam memilih merek handphone.

Faktor ketujuh dinamakan faktor garansi yang terdiri dari harga yang sesuai dengan harga pasaran $\left(\mathrm{X}_{2}\right)$, dan garansi produk yang terjamin $\left(\mathrm{X}_{19}\right)$. Faktor ketujuh mampu menjelaskan varians sebesar 4,325\%. Pada faktor ketujuh ini harga handphone yang sesuai dengan harga pasarannya menjadi pertimbangan konsumen dalam memilih merek handphone.

Ada tujuh faktor yang memengaruhi konsumen dalam memilih merek handphone dari hasil analisis faktor, sedangkan berdasarkan landasan teori dalam penelitian ini ada enam faktor. Terlihat bahwa setelah dilakukan analisis faktor didapat satu faktor baru, kemungkinan hal ini disebabkan karena indikator-indikator dari enam faktor yang berdasarkan landasan teori pada penelitian ini merupakan indikator-indikator variabel yang tidak saling berkorelasi, sedangkan indikatorindikator yang dikelompokkan kedalam faktor yang dihasilkan dari analisis faktor merupakan indikator-indikator yang saling berkorelasi 
dalam faktor tersebut maka dapat memunculkan faktor baru seperti halnya dalam penelitian ini yaitu faktor daya tahan produk.

\section{KESIMPULAN}

Berdasarkan hasil dan pembahasan dalam penelitian ini, maka didapat kesimpulan bahwa ada tujuh faktor yang terbentuk. Ketujuh faktor tesebut adalah faktor kualitas, merek, fitur, daya tahan produk, bentuk atau model, harga, dan garansi. Ketujuh faktor mampu menjelaskan secara bersama-sama keragaman total dari indikator yang ada sebesar $64,939 \%$. Faktor kualitas menjadi faktor yang dominan memengaruhi konsumen dalam memilih merek handphone yang terdiri dari delapan indikator. Pada faktor kualitas ini kualitas gambar yang diambil yang sangat menjadi pertimbangan konsumen dalam memutuskan memilih merek handphone tersebut.

Diharapkan hasil penelitian ini dapat menjadi informasi bagi perusahaan terkait dalam mengembangkan produk handphone dengan meningkatkan mutu produk dari segi kualitas dari masing-masing merek handphone yang menjadi faktor dominan atau faktor lainnya yang memengaruhi, agar dapat bersaing dengan merek handphone lainnya dan dapat memenuhi keinginan konsumen akan sebuah produk handphone yang diinginkan.

\section{DAFTAR PUSTAKA}

[1] Kotler, P \& Amstrong, G. 2001. Prinsipprinsip Pemasaran. Edisi Kedelapan, Jilid 2. Jakarta: Erlangga. Penerjemah: Sihombing, Domas.

[2] Tjiptono, F. 2001. Strategi Pemasaran. Yogyakarta: Andi Offset.

[3] Widarjono, Agus. 2010. Analisis Statistika Multivariat Terapan. Yogyakarta : STIM YKPN.

[4] Hair, J.F., Tatham, R.L., Anderson, R.E., \& Black, W. 1998. Multivariate Data Analysis. Fifth Edition. New Jersey: Pearson Prentice Hall
[5] Chatfield. C., \& A. Collins. 1980. Introduction to Multivariate Analisys. New York: Chapman and Hall.

[6] Purwandari, E. Kristi. 1998. Pendekatan Kualitatif dalam Penelitian Psikologi. Jakarta: Lembaga Pengembangan Sarana Pengukuran dan Pendidikan Psikologi, Fakultas Psikologi UI (LPSP3).

[7] Sujana, N. 2009. Analisis Faktor-Faktor yang Memengaruhi Konsumen dalam Pemilihan Merek Handphone (Studi Kasus pada Mahasiswa Universitas Muhammadiyah Semarang) [Skripsi]. 